\title{
Transient systolic hypertension after aortic valve replacement
}

\author{
M. J. McQueen, M. E. Watson, and W. H. Bain \\ From the Cardiac Surgical Unit, University Department of Surgery, Glasgow Royal Infirmary
}

Transient systolic hypertension, particularly during the 6 hours after operation, was found to be a significant complication in a series of 33 consecutive cases of aortic valve replacement. This rise in systolic blood pressure occurred in spite of treatment and was more common in cases of predominant aortic stenosis. It was not found after mitral valve replacement and there was no difference be-

$\checkmark$ tween the mitral and aortic groups 3 weeks after operation. We believe that the hypertension is due to an increase in peripheral vascular resistance in the postoperative period in patients with a powerful left ventricle.

We noted that transient systolic hypertension was a striking feature of the early postoperative course in some patients after aortic valve replacement.

Though these patients are recognized to have a higher cardiac index immediately after operation than those who have had mitral valve operations (Bristow et al., 1964; Austen et al., I966a, b; Kloster et al., I966; Rastelli and Kirklin, 1966, 1967; Mueller et al., 1968, 1970), the pattern of increase in systemic blood pressure which occurs in the first 6 hours in the intensive care area has not been documented.

\section{Patients and methods}

The postoperative records of 53 patients were studied. Of these, 33 had aortic valve replacement, and the remaining 20 had mitral valve replacement. Both groups were operated upon using a haemodilution bypass technique and anoxic cardioplegia during the insertion of the prosthesis (Starr-Edwards).

A Teflon cannula introduced into a radial artery early in the operation was used to allow continuous monitoring of the pulse wave form and pressures for at least 48 hours. Pressures were measured using a Statham P23 Db transducer and a Sanborn 780-9 display. Patency of the cannula was maintained by the intermittent infusion of heparin-saline through a Hughes pump.

Frequent measurements of the blood gases were made on arterial samples and all blood lost and transfused was charted. All drugs given were carefully noted.

- The cardiac output was measured in 14 patients using a dye-dilution technique with indocyanine green and a Water's densitometer.

Received 30 March 1971.
Each patient was weighed before operation. Other factors recorded, though not discussed in this study, were electrocardiogram, central venous pressure, rectal and skin temperature, serum potassium, haematocrit, the volume of clear fluid infused, and the urine output.

\section{Results}

The pattern of change in the arterial blood pressure after valve replacement is summarized in Table I and shown graphically in Fig. I. The systolic pressures were significantly higher in the aortic group both before operation $(P<0.001)$ and during the first 6 hours after operation $(P<0.001)$. There were no significant differences in the diastolic pressures between mitral and aortic cases.

The patients in the aortic group were further subdivided according to the dominant valve lesion, as noted at operation. In 9 cases stenosis predominated, and in 24 incompetence was the main defect (Table 2 and Fig. 2). Where aortic stenosis was the dominant lesion, there was a significantly higher systolic pressure during the first 6 hours after operation compared with predominant incompetence $(\mathbf{P}<0.02)$. Preoperatively the diastolic pressures were, of course, significantly lower in patients with predominant aortic incompetence $(P<0.01)$.

Drug therapy All the patients were given morphine frequently in small intravenous doses as an analgesic and to allay anxiety. Those who had aortic valve replacement received an average of $0.37 \mathrm{mg}$ morphine per $\mathrm{kg}$ body weight during the first 12 hours, while the mitral valve replacement patients 
TABLE I Means and standard deviations of arterial pressures $(\mathrm{mmHg})$ before and after replacement of aortic or mitral valve

\begin{tabular}{|c|c|c|c|c|c|c|c|c|}
\hline Type of case & $\begin{array}{l}\text { No. of } \\
\text { cases }\end{array}$ & & $\begin{array}{l}\text { Before } \\
\text { operation }\end{array}$ & $\begin{array}{l}\text { Immed. } \\
\text { postop. }\end{array}$ & $\begin{array}{l}\text { Average } \\
\text { over next } \\
6 \text { hours }\end{array}$ & $\begin{array}{l}\text { I } 2 \text { hours } \\
\text { postop. }\end{array}$ & $\begin{array}{l}24 \text { hours } \\
\text { postop. }\end{array}$ & $\begin{array}{l}3 \text { weeks } \\
\text { postop. }\end{array}$ \\
\hline & & & Mean $S D$ & Mean $S D$ & Mean $S D$ & Mean $S D$ & Mean $S D$ & Mean $S D$ \\
\hline $\begin{array}{l}\text { Aortic valve replace- } \\
\text { ment } \\
\text { Mitral valve replace- } \\
\text { ment }\end{array}$ & $\begin{array}{l}33 \\
20\end{array}$ & $\begin{array}{l}\text { Systolic } \\
\text { Diastolic } \\
\text { Systolic } \\
\text { Diastolic }\end{array}$ & $\begin{array}{r}142 \pm 24 \\
70 \pm 20 \\
121 \pm 12 \\
76 \pm 8\end{array}$ & $\begin{array}{r}128 \pm 21 \\
82 \pm 13 \\
122 \pm 18 \\
76 \pm 14\end{array}$ & $\begin{array}{c}146 \pm 20 \\
80 \pm 8 \\
126 \pm 9 \\
73 \pm 5\end{array}$ & $\begin{array}{r}125 \pm 8 \\
69 \pm 17 \\
126 \pm 20 \\
74 \pm 11\end{array}$ & $\begin{array}{r}138 \pm 22 \\
78 \pm 10 \\
130 \pm 12 \\
76 \pm 4\end{array}$ & $\begin{array}{l}120 \pm 8 \\
73 \pm 19 \\
\text { I20 } \pm \text { II } \\
74 \pm 6\end{array}$ \\
\hline
\end{tabular}

received $0.32 \mathrm{mg}$ per $\mathrm{kg}$ body weight during the same time.

In some patients promazine and/or promethazine were added, principally for their peripheral vasodilator effects when systolic hypertension was associated with pale extremities and empty superficial veins, despite a supranormal central venous pressure. Twenty $(60.6 \%)$ of the aortic patients received promazine and/or promethazine, while only $2(10 \%)$ of the mitral patients required this additional therapy.

Where the systolic hypertension exceeded $150 \mathrm{mmHg}$ and was associated with peripheral pallor and a high central venous pressure, hexamethonium bromide was administered. None of the mitral patients required hexamethonium, but $7(21 \cdot 2 \%)$ of the aortic patients required it in doses ranging from 5 $\mathrm{mg}$ to $46 \mathrm{mg}$ over the first I2 hours: 4 of those receiving hexamethonium had predominant aortic stenosis and represented 44 per cent of the stenosis group, while the other 3 represented 12.6 per cent of those with predominant incompetence.

Cardiac index We found that the mean cardiac index was higher after aortic than after mitral valve replacement. The mean value for the aortic group was $2 \cdot 21 . / \mathrm{m}^{2}$ per min (SD 0.4I) and for the mitral group was $\mathrm{I} \cdot 77 \mathrm{l} . / \mathrm{m}^{2}$ per $\min (\mathrm{SD} 0.44$ ). Though these figures are not statistically significant in this small series, they are in accord with the results of larger series of patients in whom cardiac index was studied after valve replacement.

$\mathrm{Po}_{2}$ and $\mathrm{Pco}_{2}$ levels All the patients were maintained on IPPV (Engstrom) until the morning of the first postoperative day, and the concentration of inspired $\mathrm{O}_{2}$ and minute volume were adjusted to keep the $\mathrm{Po}_{2}$ and $\mathrm{PCO}_{2}$ within reasonable limits. Only 3 patients, all of whom were in the mitral group, had an average $\mathrm{PCO}_{2}>50 \mathrm{mmHg}$ during this time and in none of the 3 was the average $\mathrm{PCO}_{2}>55$ $\mathrm{mmHg}$, neither were they hypertensive. The average $\mathrm{Po}_{2}$ in all cases was $\geqslant 80 \mathrm{mmHg}$ during this time.

Blood loss replacement There was no significant difference between the groups. Mitral cases received an average of 6.5 litres of whole blood and aortic cases an average of 7 litres. When blood was given rapidly calcium chloride ( $9 \mathrm{mM}$ per litre of blood transfused) was infused to counteract the effect of citrate in the transfused blood.

TABLE 2 Means and standard deviations of arterial pressures ( $\mathrm{mmHg}$ ) in cases of predominant stenosis and incompetence of aortic valve

\begin{tabular}{|c|c|c|c|c|c|c|c|c|}
\hline \multirow[t]{2}{*}{ Type of case } & \multirow[t]{2}{*}{$\begin{array}{l}\text { No. of } \\
\text { cases }\end{array}$} & & $\begin{array}{l}\text { Before } \\
\text { operation }\end{array}$ & $\begin{array}{l}\text { Immed. } \\
\text { postop. }\end{array}$ & $\begin{array}{l}\text { Average } \\
\text { over next } \\
6 \text { hours }\end{array}$ & $\begin{array}{l}\text { I2 hours } \\
\text { postop. }\end{array}$ & $\begin{array}{l}24 \text { hours } \\
\text { postop. }\end{array}$ & $\begin{array}{l}3 \text { weeks } \\
\text { postop. }\end{array}$ \\
\hline & & & Mean $S D$ & Mean $S D$ & Mean $S D$ & Mean $S D$ & Mean $S D$ & Mean $S D$ \\
\hline Aortic incompetence & 24 & $\begin{array}{l}\text { Systolic } \\
\text { Diastolic } \\
\text { Systolic } \\
\text { Diastolic }\end{array}$ & $\begin{array}{c}138 \pm \text { I I } \\
86 \pm 4 \\
144 \pm 24 \\
65 \pm \text { I8 }\end{array}$ & $\begin{array}{r}131 \pm 10 \\
79 \pm 13 \\
128 \pm 16 \\
83 \pm 20\end{array}$ & $\begin{array}{c}158 \pm 18 \\
80 \pm 10 \\
141 \pm 23 \\
80 \pm 7\end{array}$ & $\begin{array}{c}\text { I I9 } \pm \text { I } 4 \\
66 \pm 4 \\
\text { I28 } \pm \text { I4 } \\
72 \pm \text { II }\end{array}$ & $\begin{array}{c}144 \pm 26 \\
76 \pm 9 \\
136 \pm 19 \\
79 \pm 8\end{array}$ & $\begin{array}{c}\text { I2I } \pm \text { I0 } \\
73 \pm 4 \\
119 \pm 14 \\
73 \pm 10\end{array}$ \\
\hline
\end{tabular}




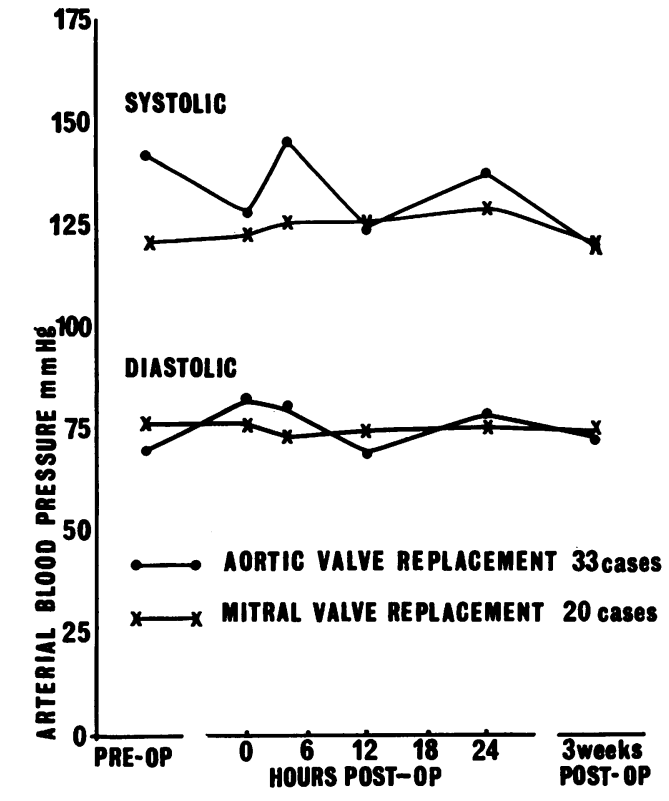

FIG. I

Cardiac rhythm A large majority of the aortic cases $(93.1 \%)$ were in sinus rhythm during the first 12 hours after operation and 82.6 per cent of them were still in sinus rhythm when they were discharged from hospital. In contrast 73.7 per cent of the mitral cases were in atrial fibrillation after operation and the same proportion remained so at the time of discharge from hospital.

Peripheral resistance during cardiopulmonary bypass This was calculated using the formula:

Peripheral vascular resistance $=$

(Mean arterial pressure - Central venous pressure) $\times 80$

\section{Pump flow}

Peripheral resistance was expressed as dynes $\mathrm{sec} \mathrm{cm}^{-5}$. The mean peripheral resistance during aortic valve replacement was $897^{\circ} 6$ dynes $\mathrm{sec} \mathrm{cm}^{-5}$ (SD 248 dynes $\mathrm{sec}$ $\mathrm{cm}^{-5}$ ) and during mitral valve replacement II34 dynes sec $\mathrm{cm}^{-5}$ (SD 333 dynes sec $\mathrm{cm}^{-5}$ ).

Within the aortic group, those with stenosis had a higher mean peripheral resistance (I069 dynes $\mathrm{sec} \mathrm{cm}^{-5}$ ) and a lower mean arterial flow ( $4.21 \mathrm{l} . / \mathrm{min})$, than those with incompetence who had a mean resistance of 828 dynes sec $\mathrm{cm}^{-5}$ and a mean arterial flow of 4.55 $1 . / \mathrm{min}$.

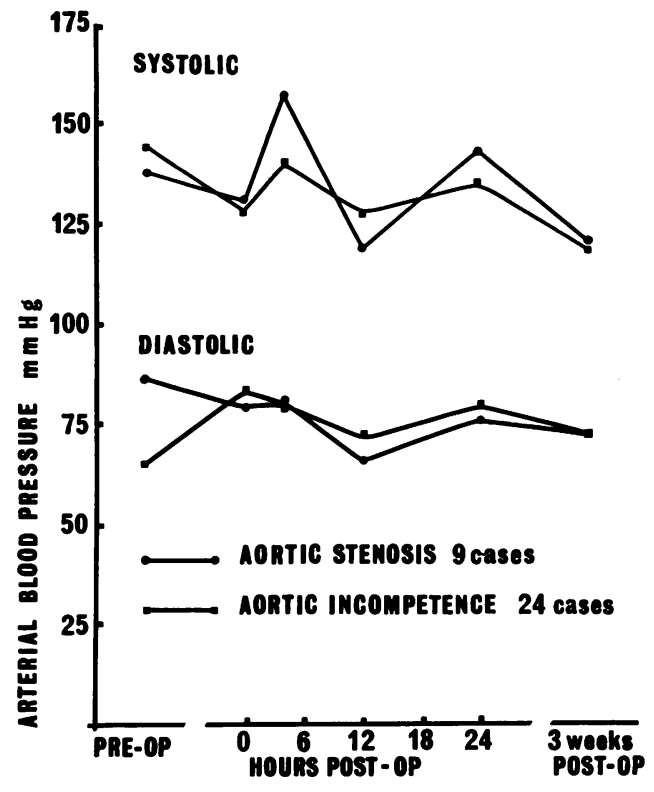

FIG. 2

Aortic valve size The size of the ball valve prosthesis was recorded in all cases. Any prosthesis of number IOA or less (orifice area $\mathrm{I} \cdot 8$ $\mathrm{cm}^{2}$ or less) was arbitrarily classified as a small valve. Of those with predominant stenosis, 62.5 per cent received a number IOA or less, whereas only 23.8 per cent of those with significant incompetence received a small valve.

\section{Discussion}

Our results show that the systolic pressures are significantly higher during the 6 hours after operation for replacement of the aortic valve than after replacement of the mitral valve. These operations were done using similar techniques and the subsequent differences in blood pressure could not be attributed to hypoxia, hypercapnia, blood requirements, or calcium chloride given at the time of transfusion. Cardiac rhythm could not be implicated as the cause of the highly significant differences between the systolic pressures of the two groups during the first 12 hours after operation, as there was no change in the predominant rhythm in each group between this time and the time of leaving hospital, when there was no difference between the systolic pressures. The difference was still evident even after the aortic group was given larger quantities of morphine, promazine, promethazine, or hexamethonium. There was also a significant difference during the same six-hour 
period between the patients in whom aortic stenosis was the dominant lesion compared with those with aortic incompetence.

We do not lay great stress on the peripheral resistance during total bypass. This is partly because the high standard deviations obtained in this study resulted in no statistically significant differences being found, but also because of the difficulty in a retrospective study of making precise allowances for factors such as the rate at which the venous blood from the patient was drained into the reservoir at the onset of bypass, the relative rates of blood loss and blood transfusion, and the effect at any time of pethidine and/or morphine given during bypass.

The two mechanisms that appear to be involved in the postoperative hypertension are increased peripheral vascular resistance and increased myocardial performance or efficiency.

Rastelli and Kirklin (1967) have shown that the peripheral vascular resistance is at its highest about 5 hours after operation. Dammann et al. (1963) have also noted high tone in systemic resistance vessels during the first few hours after replacement of the aortic valve. These findings are in agreement with the fact that the highest systolic pressures and the highest mean arterial pressures encountered in this study were found during this same time interval.

The high peripheral vascular resistance may be due to endogenous catecholamine release associated with arousal from anaesthesia. The decline in peripheral vascular resistance and blood pressure seen 12 hours after operation

FIG. 3 Systolic and diastolic pressures in one patient given intravenous hexamethonium bromide.

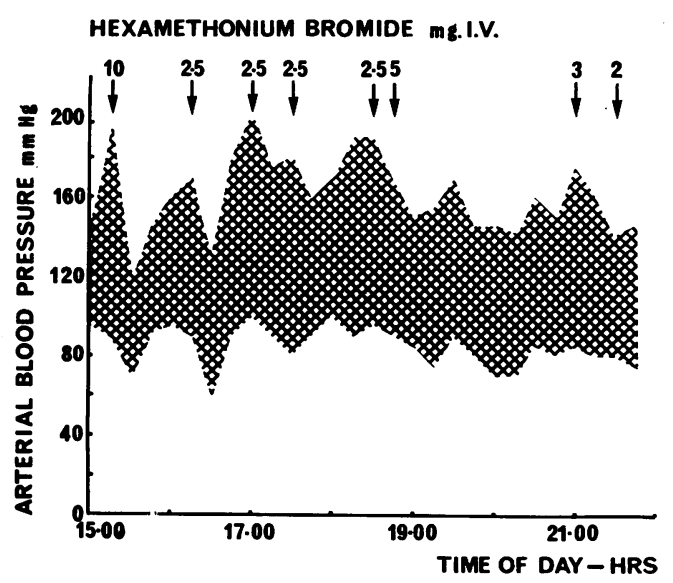

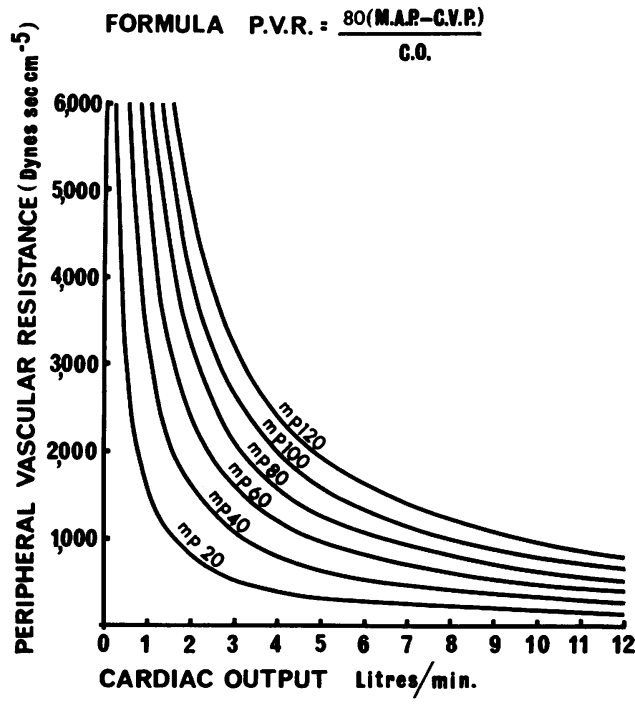

FIG. 4 The relation between cardiac output and peripheral resistance at various levels of perfusion pressure. PVR, peripheral vascular resistance (dynes sec $\mathrm{cm}^{-5}$ ); MAP, mean arterial pressure $(\mathrm{mmHg}) ; \mathrm{CVP}$, central venous pressure $(\mathrm{mmHg}) ; \mathrm{mp}$, arteriovenous pressure gradient in $\mathrm{mmHg}(M A P-C V P)$; $\mathrm{CO}$, cardiac output (l./min).

FIG. 5 Changes in peripheral vascular resistance (PVR), blood pressure, and cardiac output mediated by hexamethonium bromide.

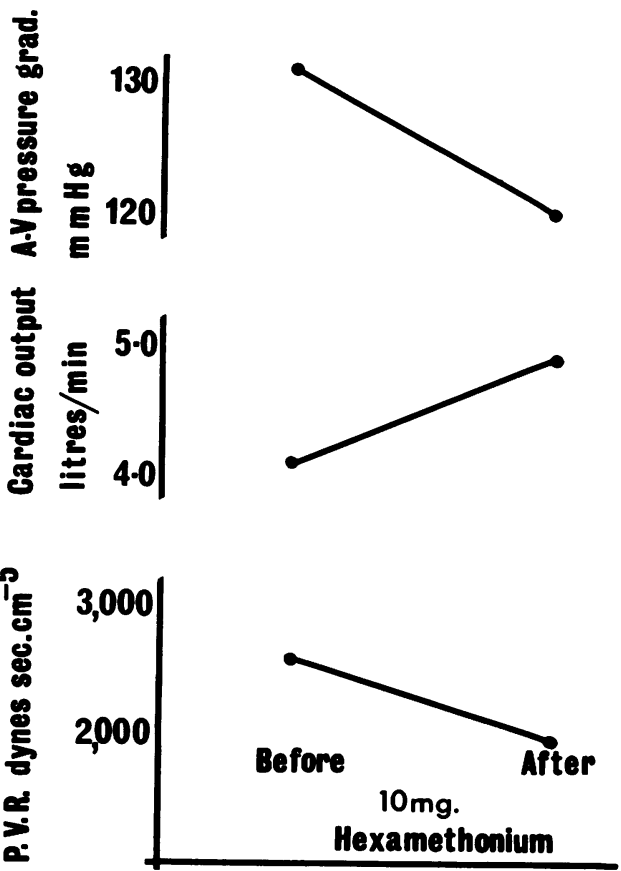


may be related to the cumulative effect of sedation, with consequent lower levels of circulating catecholamines, and the fact that there are fewer staff around at that time to stimulate the patient could also be an important factor.

We suggest that the greater incidence of systolic hypertension in cases of predominant aortic stenosis is possibly due to the ability of the thick hypertrophied left ventricle to maintain output against a high peripheral resistance, in contrast to the more dilated and less obviously hypertrophied left ventricle associated with aortic incompetence. The larger valve required by the latter group is a further reflection of the chamber size in each group. We also believe that the transient hypertension is not seen in cases after mitral valve replacei ment because such patients have a longer history of myocardial decompensation and they lack the myocardial reserve to respond to catecholamine stimulation and maintain a good output against increased peripheral vascular resistance. This view is supported by the finding of a lower cardiac index in mitral patients.

The clinical problem of this transient systolic hypertension with its attendant risks of increased blood loss from the thoracotomy and aortotomy sites, and increased demands on the ventricular myocardium, can be better appreciated by referring to the records of one patient during the 6 hours after operation (Fig. 3). This man was given hexamethonium, as its effects are well known and because small frequent doses reduce the risk of prolonged hypotension due to overdosage or abnormal sensitivity. In a normal person in the recumbent posture, the drug produces very little change in blood pressure, but in a patient with arterial hypertension a moderate reduction may be noted. Any reduction which occurs in a recumbent posture can be accounted for by a reduction in the total peripheral vascular resistance. By reducing the raised peripheral resistance less ventricular work is required. This patient's systemic blood pressure was gradually reduced to $150 / 75 \mathrm{mmHg}$ over 7 hours.

It is perhaps worth explaining that while it is reassuring to see high systemic pressures after operation, the cardiac output is not necessarily optimal in such a situation, and the relation between mean blood pressure and cardiac output at various levels of peripheral vascular resistance are shown in Fig. 4. In this patient the reduction of peripheral vascular resistance and blood pressure mediated by Io $\mathrm{mg}$ hexamethonium was associated with a significant increase in cardiac output (Fig. 5).

The contribution to the systemic changes described in this study of the presence in the aortic root of prostheses, the smaller of which cause a systolic pressure gradient, cannot be estimated.

Finally, all these patients are followed up 2 months, 8 months, and yearly after their discharge from hospital, and only one is being treated for systemic hypertension, for which he was also being treated before his operation.

\section{References}

Austen, W. G., Corning, H. B., Moran, J. M., Sanders, C. A., and Scannell, J. G. (I966a). Cardiac haemodynamics immediately following aortic valve surgery. Fournal of Thoracic and Cardiovascular Surgery, 5I, 46I.

Austen, W. G., Corning, H. B., Moran, J. M., Sanders, C. A., and Scannell, J. G. (1966b). Cardiac haemodynamics immediately following mitral valve surgery. Fournal of Thoracic and Cardiovascular Surgery, 51, 468.

Bristow, J. D., McCord, C. W., Starr, A., Ritzmann, L. W., and Griswold, H. E. (1964). Clinical and haemodynamic results of aortic valvular replacement with a ball-valve prosthesis. Circulation, 29, Suppl. I, 36.

Dammann, J. F., Thung, N., Christlieb, I. I., Littlefield, J. B., and Muller, W. H. (1963). The management of the severely ill patient after open-heart surgery. Fournal of Thoracic and Cardiovascular Surgery, 45, 80 .

Kloster, F. E., Bristow, J. D., Starr, A., McCord, C. W., and Griswold, H. E. (1966). Serial cardiac output and blood volume studies following cardiac valve replacement. Circulation, 33, 528.

Mueller, H., Gianelli, S., Ayres, S. M., Conklin, E. F., and Gregory, J. J. (1968). Effect of isoproterenol on ventricular work and myocardial metabolism in the postoperative heart. Circulation, 37, Suppl. II, 146.

Mueller, H. S., Gregory, J. J., Gianelli, S., and Ayres, S. M. (1970). Systemic haemodynamic and myocardial metabolic effects of isoproterenol and angiotensin after open-heart surgery. Circulation, 42, $49 \mathrm{r}$.

Rastelli, G. C., and Kirklin, J. W. (I966). Haemodynamic state early after prosthetic replacement of mitral valve. Circulation, 34, 448.

Rastelli, G. C., and Kirklin, J. W. (1967). Haemodynamic state early after replacement of aortic valve with ball-valve prosthesis. Surgery, 6r, 873 .

Requests for reprints to Dr. M. J. McQueen, Cardiac Surgical Unit, Glasgow Royal Infirmary, Castle Street, Glasgow C.4. 